\title{
Telmisartan inhibits NSCLC A549 cell proliferation and migration by regulating the PI3K/AKT signaling pathway
}

\author{
SUOLIN ZHANG ${ }^{1}$ and YAYAN WANG ${ }^{2}$ \\ ${ }^{1}$ Department of Chest Surgery, The Second Hospital of Shandong University, Jinan, Shandong 250000; \\ ${ }^{2}$ Department of Respiratory Medicine, Affiliated Hospital of Yanbian University, Yanji, Jilin 133000, P.R. China
}

Received July 21, 2017; Accepted December 12, 2017

DOI: $10.3892 / 01.2018 .8002$

\begin{abstract}
Expression of angiotensin II (Ang II), a key biological peptide in the renin-angiotensin system, is closely associated with the occurrence and development of cancer. Ang II binds two receptor subtypes, the Ang II type 1 receptor (AT1R) and the AT2R, to mediate a series of biological effects. Telmisartan, a specific AT1R blocker, has been reported to have potential as an anticancer drug for treating renal cancer. In the present study, whether telmisartan had an effect on non-small cell lung cancer (NSCLC) cell proliferation and migration was investigated. The Cell Counting kit- 8 assay revealed that telmisartan significantly inhibited the growth of the NSCLC A549 cell line in a time- and dose-dependent manner. In a transwell assay, telmisartan significantly inhibited cellular invasion and migration. Furthermore, it was determined that the expression of the anti-apoptotic protein B-cell lymphoma was decreased, and that of the pro-apoptotic proteins caspase-3 and Bcl-associated X increased in the A549 cells treated with telmisartan. Additionally, levels of phosphorylated RAC serine/threonine-protein kinase (p-AKT), p-mechanistic target of rapamycin, p70-S6 kinase and cyclin D1 was decreased in the telmisartan-treated group. Therefore, the current study reveals that telmisartan-induced NSCLC apoptosis may be regulated via the phosphoinositide 3-kinase/AKT signaling pathway, which indicates that it may be a potential novel drug for clinical NSCLC treatment.
\end{abstract}

Correspondence to: Dr Yayan Wang, Department of Respiratory Medicine, Affiliated Hospital of Yanbian University, 1327 Bureau Street, Changyi, Yanji, Jilin 133000, P.R. China

E-mail: 15526770312@163.com

Abbreviations: Ang II, angiotensin II; NSCLC, non-small cell lung cancer; AT1R, angiotensin II type 1 receptor; AT2R, angiotensin II type 2 receptor; ARBs, angiotensin II receptor blockers

Key words: telmisartan, angiotensin II, non-small cell lung cancer, angiotensin II type 1 receptor, angiotensin II receptor blockers, phosphoinositide 3-kinase/RAC serine/threonine protein kinase

\section{Introduction}

Lung cancer, the most common type of cancer, has the highest morbidity rate among all types of malignancies worldwide $(1,2)$, accounting for $30 \%$ of all incidences of cancer-associated mortality (3). In clinical practice, the two major types of lung cancer are small cell lung cancer (SCLC) and non-SCLC (NSCLC) (4), of which NSCLC accounts for $\sim 80 \%$ of all lung cancer cases (5). Current therapies for NSCLC include chemotherapy, radiotherapy, targeted therapy and surgery, which are used alone or in combination (6). Despite the use of these therapies, the overall 5-year survival rate of NSCLC remains low, at $15 \%$ (7). Owing to the development of drug resistance and the severe side effects experienced by patients, effective and safe novel agents are required for the treatment of NSCLC (1).

Angiotensin II (Ang II), a key biological peptide in the renin-angiotensin system, is a vasoconstrictor that controls cardiovascular function and renal homeostasis (8). Ang II receptor blockers (ARBs) are extensively used as anti-hypertensive drugs (9). Studies have reported that angiogenesis is essential for tumor progression and metastasis $(10,11)$. Furthermore, studies have demonstrated that ARBs have the potential possibility to restrain the growth of several types of cancer cells $(12,13)$. Ang II binds two receptor subtypes, the Ang II type 1 receptor (AT1R) and the Ang II type 2 receptor (AT2R), to mediate a series of biological effects (14). AT1R mediates the main functions of Ang II, including tumor growth and angiogenesis (15). Treatment with telmisartan, a specific AT1R blocker, leads to apoptosis and the inhibition of cell cycle progression in cancer cells $(16,17)$. It has been reported that telmisartan has anti-proliferative activity in prostate and renal cell cancer $(18,19)$; however, there are few relevant reports on the anti-proliferative activity of telmisartan in NSCLC cells (20).

In the present study, the Cell Counting Kit-8 (CCK-8), Transwell assay and western blot analysis was used to determine whether telmisartan treatment could inhibit the proliferation and invasion of A549 NSCLC cells, which may be regulated via phosphoinositide 3-kinase (PI3K)/RAC serine/threonine-protein kinase (AKT) inhibition-induced apoptosis.

\section{Materials and methods}

Cell lines and cell culture. The NSCLC A549 cell line was obtained from the American Type Culture Collection 
(Manassas, VA, USA). Cells were cultured in Dulbecco's Modified Eagle's Medium (DMEM; Hyclone; GE Healthcare Life Sciences, Logan, UT, USA) supplemented with $10 \%$ fetal bovine serum (FBS; Gibco; Thermo Fisher Scientific, Inc., Waltham, MA, USA), $100 \mathrm{U} / \mathrm{ml}$ penicillin (Sigma-Aldrich; Merck KGaA, Darmstadt, Germany) and $0.1 \mathrm{mg} / \mathrm{ml}$ streptomycin (Sigma-Aldrich; Merck KGaA). All cell lines were incubated at $37^{\circ} \mathrm{C}$ in a humidified atmosphere containing $5 \%$ $\mathrm{CO}_{2}$. When cells entered into the logarithmic growth phase, they were washed three times with PBS and digested with $0.25 \%$ trypsin (Beijing Solarbio Science \& Technology, Co., Ltd., Beijing, China). When the cells detached, DMEM was re-added to terminate digestion and resuspended the cells into single cell suspension, then the cells $\left(100 \mu 1,1 \times 10^{5}\right)$ were seeded into a 6-well plate for subsequent experiments.

Cell Counting Kit-8 (CCK-8) proliferation assay. A $100 \mu 1$ suspension of A549 cells was seeded into 96-well plate with the standard 1,000 cells/well. In this assay, 5 groups were used, which were control (DMEM only), vehicle [0.1\% dimethyl sulfoxide (DMSO); Ameresco, Inc., Framingham, MA, USA)] and 0.2, 2 and $20 \mu \mathrm{M}$ telmisartan (MedChem Express, Princeton, NJ, USA). Following this, cells were cultured in a $\mathrm{CO}_{2}$ incubator and the cell viability was detected at 24,48 , $72 \mathrm{~h}$. A total of $10 \mu \mathrm{l} \mathrm{CCK-8} \mathrm{(Beijing} \mathrm{Solarbio} \mathrm{Science} \mathrm{\&}$ Technology, Co., Ltd.) reagent was added into each well and the plates were incubated at $37^{\circ} \mathrm{C}$ for $1.5 \mathrm{~h}$. The optical density value was measured at a wavelength of $450 \mathrm{~nm}$ using a microplate reader and a proliferation curve was plotted. The assay was performed in triplicate. In the following experiments, the negative control (NC) group was treated with $0.1 \%$ DMSO, and the treated group with $20 \mu \mathrm{M}$ telmisartan.

Cell invasion and migration assessed via transwell assay. A total of $100 \mu \mathrm{l}$ Matrigel (diluted 1:6 in serum-free DMEM; BD Biosciences, Franklin Lakes, NJ, USA), was melted overnight and then added to the upper chamber of a 24-well transwell plate (EMD Millipore, Billerica, MA, USA). Following shaking, the Matrigel was placed into $37^{\circ} \mathrm{C} \mathrm{CO}_{2}$ incubator cultivating for 4-6 $\mathrm{h}$ until the gel set, and then the culture medium was dried. The cells, which had been treated with $20 \mu \mathrm{M}$ telmisartan for $24 \mathrm{~h}$, were prepared using serum-free DMEM in a cell suspension. A total of $100 \mu 1\left(1 \times 10^{5}\right)$ cell suspension were added to the upper chamber of the transwell. Following this, $500 \mu \mathrm{l}$ complete DMEM (containing 10\% FBS) was mixed into the bottom chamber of the transwell. Cells were incubated for $24 \mathrm{~h}$, then the transwell was taken out and the remaining cells in the upper chamber were removed with a cotton swab. After washing with PBS, the cells were fixed in $4 \%$ paraformaldehyde for $30 \mathrm{~min}$ at room temperature, and stained with $0.1 \%$ crystal violet for $20 \mathrm{~min}$ at room temperature. Following washing with PBS, five clear fields of vision were selected random using a light microscope (magnification, $\mathrm{x} 200$ ), and images were captured to observe the cell count.

The migration experiment procedure was similar to the invasion assay; however, the Matrigel was not applied and the 5,000 cells were seeded in the upper chambers.

Cell apoptosis assay. Apoptotic A549 cells were evaluated using an Annexin V-fluorescein isothiocyanate
(Annexin V-FITC)/propidium iodide (PI) Apoptosis Detection kit (4A Biotech Co. Ltd., Beijing, China) according to the manufacturer's protocol. The NC group was treated with $0.1 \%$ DMSO. Following the treatment of A549 cells with $20 \mu \mathrm{M}$ telmisartan and digested with $0.25 \%$ trypsin (without EDTA), collected in a centrifuge tube, centrifuged at $800 \mathrm{xg}$ at $4^{\circ} \mathrm{C}$ for $5 \mathrm{~min}$, resuspended in $4^{\circ} \mathrm{C}$ pre-cooled PBS and finally centrifuged once again at $800 \mathrm{x} \mathrm{g}$ at $4^{\circ} \mathrm{C}$ for $5 \mathrm{~min}$. The supernatant was aspirated and the cells were resuspended in $1 \mathrm{x}$ Binding Buffer (Biomiga Inc., San Diego, CA, USA). Cell density was regulated to $\sim 1 \times 10^{6} / \mathrm{ml}$. A total of $100 \mu \mathrm{l}$ cell suspension was added into a 5-ml flow tube and stained with $5 \mu$ l Annexin V-FITC (Apoptosis Detection kit) for $5 \mathrm{~min}$ at room temperature in the dark. Next, cells were stained with $10 \mu \mathrm{l}$ propidium iodide (PI) and incubated at room temperature in the dark for $5 \mathrm{~min}$, and $400 \mu \mathrm{l}$ PBS was added to detect cells. The cells were then assessed using a flow cytometer and results were analyzed using FlowJo software (version 7.6.3; FlowJo, LLC, Ashland, OR, USA). The assay was performed in triplicate.

Western blot analysis. When the cell confluence was $\sim 80 \%$, the cells were treated with $20 \mu \mathrm{M}$ telmisartan or $0.1 \%$ DMSO. After $24 \mathrm{~h}$, the 6-well plate was placed on ice. Next, Radioimmunoprecipitation Assay lysis buffer (including protease inhibitor; Beijing ComWin Biotech Co., Ltd., Beijing, China) was added to extract protein. The protein concentration was measured using the BCA Protein Assay kit (Beijing ComWin Biotech Co., Ltd.). Next, the protein was heated at $95^{\circ} \mathrm{C}$ for $5 \mathrm{~min}$. A total of $\sim 20 \mu \mathrm{g}$ protein per lane was separated using $10 \%$ SDS-PAGE and transferred onto a polyvinylidene fluoride membrane. The membrane was blocked using 5\% skimmed milk for $1 \mathrm{~h}$ at room temperature. Next, the membrane was incubated with the primary antibodies listed below at $4^{\circ} \mathrm{C}$ overnight. The membrane was then washed three times for $5 \mathrm{~min}$ with $0.1 \%$ Tween 20 -TBS, then incubated with the appropriate secondary antibodies, listed below, for $1 \mathrm{~h}$ at room temperature. Following washing of the membrane (as aforementioned), bands were visualized using an enhanced chemiluminescence reagent (PerkinElmer, Inc., Waltham, MA, USA). Quantity One software (version 4.62; Bio-Rad Laboratories, Inc., Hercules, CA, USA) was used to perform densitometry analysis.

The following antibodies were used. Primary antibodies: AKT (dilution, 1:1,000; cat. no. 4691; Cell Signaling Technology, Inc., Danvers, MA, USA), phosphorylated (p)-AKT (dilution, 1:1,000; cat. no. 4060; Cell Signaling Technology, Inc.), mechanistic target of rapamycin (mTOR) (dilution, 1:1,000; cat. no. 2983; Cell Signaling Technology, Inc.), p-mTOR (dilution, 1:1,000; cat. no. 5536; Cell Signaling Technology, Inc.), Bcl-2 (dilution, 1:1,000; cat. no. 12789-1-AP; ProteinTech Group, Inc., Chicago, IL, USA), Bax (dilution 1:1,000; cat. no. 23931-1-AP; ProteinTech Group), caspase-3 (dilution, 1:1,000; cat. no. 25546-1-AP; ProteinTech Group), cyclin D1 (dilution, 1:1,000; cat. no. 60186-1-Ig; ProteinTech Group), p70 S6 kinase (p70S6K) (dilution, 1:1,000; cat. no. 14485-1-AP; ProteinTech Group), Tubulin (dilution, 1:5,000; cat. no. 10759-1-AP; ProteinTech Group); Secondary antibodies: horseradish peroxidase-labeled goat anti-rabbit (dilution 1:5,000; cat. no. SA00001-2; ProteinTech Group). The relative expression of each protein was normalized to tubulin levels in each sample. 
Statistical analysis. Statistical analysis of experimental data was performed using SPSS 18.0 (SPSS, Inc., Chicago, IL, USA). Data are presented as mean \pm standard deviation. Student's t-test was used to analyze the difference between the telmisartan-treatment and NC groups. Analysis of variance with post hoc Fisher's least significant difference test was used for multiple comparisons. $\mathrm{P}<0.05$ was considered to indicate a statistically significant difference.

\section{Results}

Telmisartan inhibits A549 cell proliferation. To evaluate the effect of telmisartan on NSCLC, the NSCLC A549 cell line was treated with $0.2,2$ and $20 \mu \mathrm{M}$ telmisartan to detect cell proliferation rates. In this experiment, the cells were measured at $24,48,72 \mathrm{~h}$. The results of the CCK- 8 proliferation assay indicated that only the $20 \mu \mathrm{M}$ telmisartan treatment group exhibited a significant reduction in the proliferation of A549 cells following $72 \mathrm{~h}(\mathrm{P}<0.05$; Fig. 1). These results demonstrated that telmisartan could effectively inhibit A549 proliferation in a dose- and time-dependent manner; therefore, $20 \mu \mathrm{M}$ telmisartan was used in the following experiments.

Telmisartan inhibits A549 cell invasion and migration. A transwell assay was used to analyze the effects of telmisartan on the invasive and migratory ability of A549. After crystal violet staining the A549 cells were reduced via the telmisartan treatment in the invasion experiment. Additionally, the cells were also reduced in the migration experiment. The number of invaded cells in the telmisartan-expressing group was less than control group ( $8 \pm 2$ vs. $46 \pm 4$ cells invaded, respectively) and indicated a significant difference $(\mathrm{P}<0.05$; Fig. 2A). The migratory capacity of cells was also inhibited in the telmisartan-expressing group compared with the control group ( $29 \pm 3$ vs. $74 \pm 5$ cells migrated, respectively), indicating the negative effect of telmisartan on the migration ability of A549 cells ( $\mathrm{P}<0.05$; Fig. 2B), compared with the control group. These results indicated that telmisartan could significantly inhibit the invasion and migration of A549.

Telmisartan promotes A549 cell apoptosis. An annexin V-FITC/PI double-staining assay was used to determine the effect of telmisartan on A549 cell apoptosis. Following the induction of serum-free apoptosis, the apoptosis rate in the telmisartan-treated group was significantly higher than that in the control group $(21.85$ vs. $5.81 \%$, respectively; $\mathrm{P}<0.05)$. In addition, it was determined that telmisartan had a greater effect on early apoptosis (17.8\%) compared with late apoptosis $(4.05 \%)$ (Fig. 3A). Furthermore, western blot analysis was used to analyze the protein expression of apoptosis regulators, including the anti-apoptotic protein $\mathrm{Bcl}-2$, and the pro-apoptotic proteins caspase- 3 and Bax (Fig. 3B). The expression of the pro-apoptotic proteins caspase- 3 and Bax increased in the telmisartan-treated group compared with the control group, whereas the expression of the anti-apoptotic protein $\mathrm{Bcl}-2$ decreased $(\mathrm{P}<0.05$; Fig. 3C-E). These results indicated that telmisartan could promote A549 cell apoptosis.

Telmisartan suppresses the PI3K pathway in A549 cells. In tumors the PI3K/AKT pathway is extremely important.

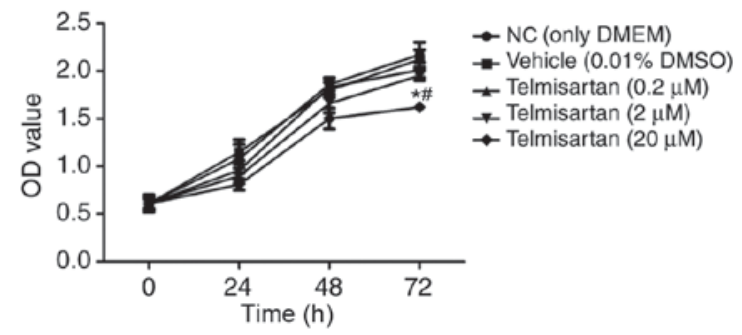

Figure 1. Telmisartan inhibited A549 cell proliferation using the Cell Counting Kit- 8 assay. ${ }^{*} \mathrm{P}<0.05$, compared with the vehicle group; ${ }^{\#} \mathrm{P}<0.05$, compared with NC group. OD, optical density; DMEM, Dulbecco's modified Eagle's medium; DMSO, dimethyl sulfoxide; NC, negative control.

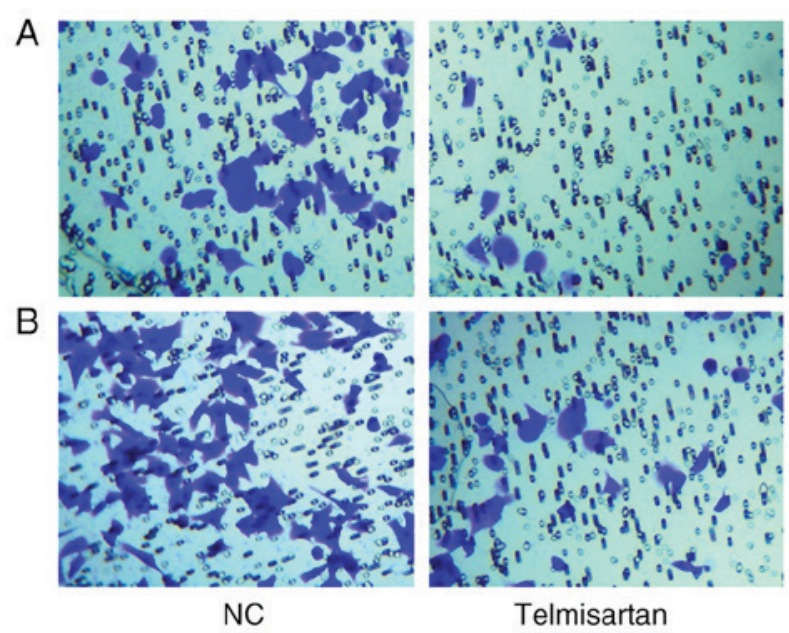

Figure 2. Telmisartan inhibits A549 cell invasion and migration. (A) Images are representative of crystal violet-stained A549 invaded cells. (B) Images representative of crystal violet-stained A549 migrated cells. Images were captured using an inverted microscope at a magnification of x100. NC, negative control.

Following telmisartan treatment, mTOR, p70S6K and cyclin D1 proteins were selected as indicators for the evaluation of the activity of the PI3K/AKT signaling pathway. The results of western blot analysis indicated that the phosphorylation level of mTOR decreased significantly in telmisartan-treated A549 cells $(\mathrm{P}<0.05)$. Similarly, the expression levels of p70S6K and cyclin D1 were decreased following telmisartan treatment $(\mathrm{P}<0.05$; Fig. 4). These results indicated that telmisartan-induced inhibition of A549 cell growth might be regulated via the PI3/AKT pathway.

\section{Discussion}

In the present study, a preliminary investigation into the effects and potential underlying molecular mechanisms of telmisartan was conducted. Telmisartan inhibited the proliferation, invasion and migration of A549 cells. Furthermore, it was demonstrated that cell apoptosis was significantly promoted via telmisartan. These effects mediated by telmisartan on A549 cells may be associated with the inhibition of the PI3K/AKT signaling pathway.

Ang II, as a vasoconstrictor, is a multifunctional and bioactive octapeptide of the renin-angiotensin system, which controls cardiovascular function and kidney homeostasis (21). The prior 
A

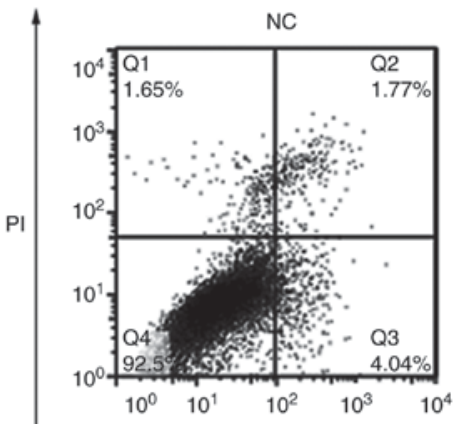

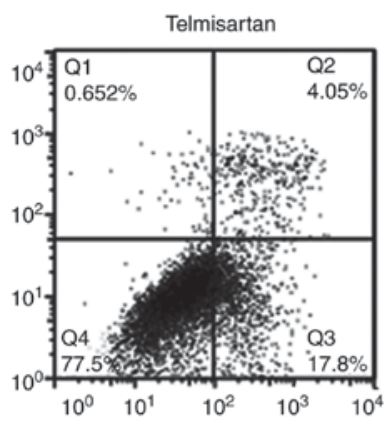

Annexin V-FITC

B

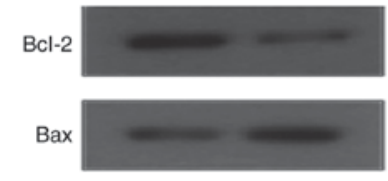

Caspase-3

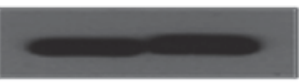

Tubulin
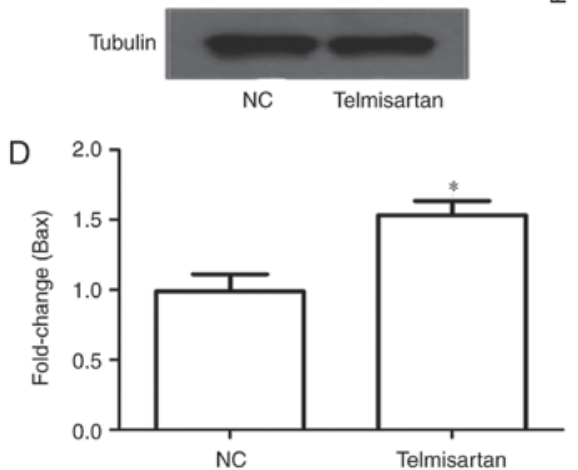

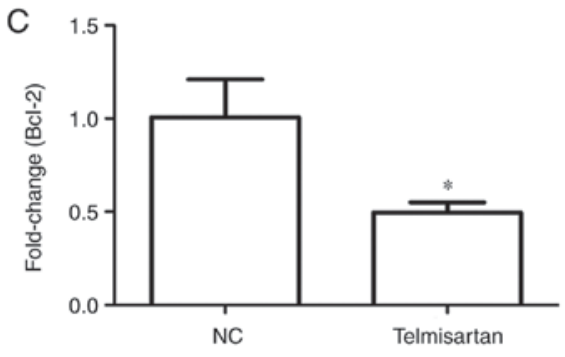

$\mathrm{E}$

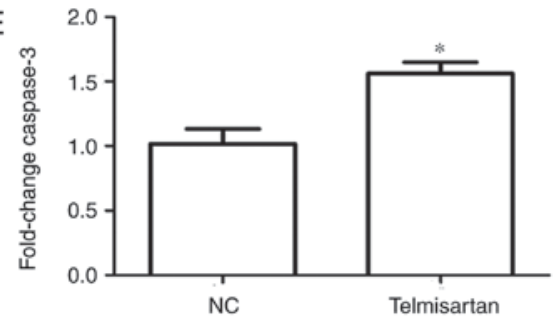

Figure 3. Telmisartan induces A549 cell apoptosis. (A) A549 cells were treated with $20 \mu \mathrm{M}$ telmisartan for $24 \mathrm{~h}$ and labeled with Annexin V-FITC and PI, followed via flow cytometric analysis. (B) Western blot analysis of A549 cells treated with telmisartan for 24 h. The band intensities were quantified. The results were normalized to the GAPDH loading control. (C-E) Relative levels of the indicated apoptosis-associated proteins. * $<<0.05$, compared with NC group. $\mathrm{NC}$, negative control; PI, propidium iodide; FITC, fluorescein isothiocyanate.
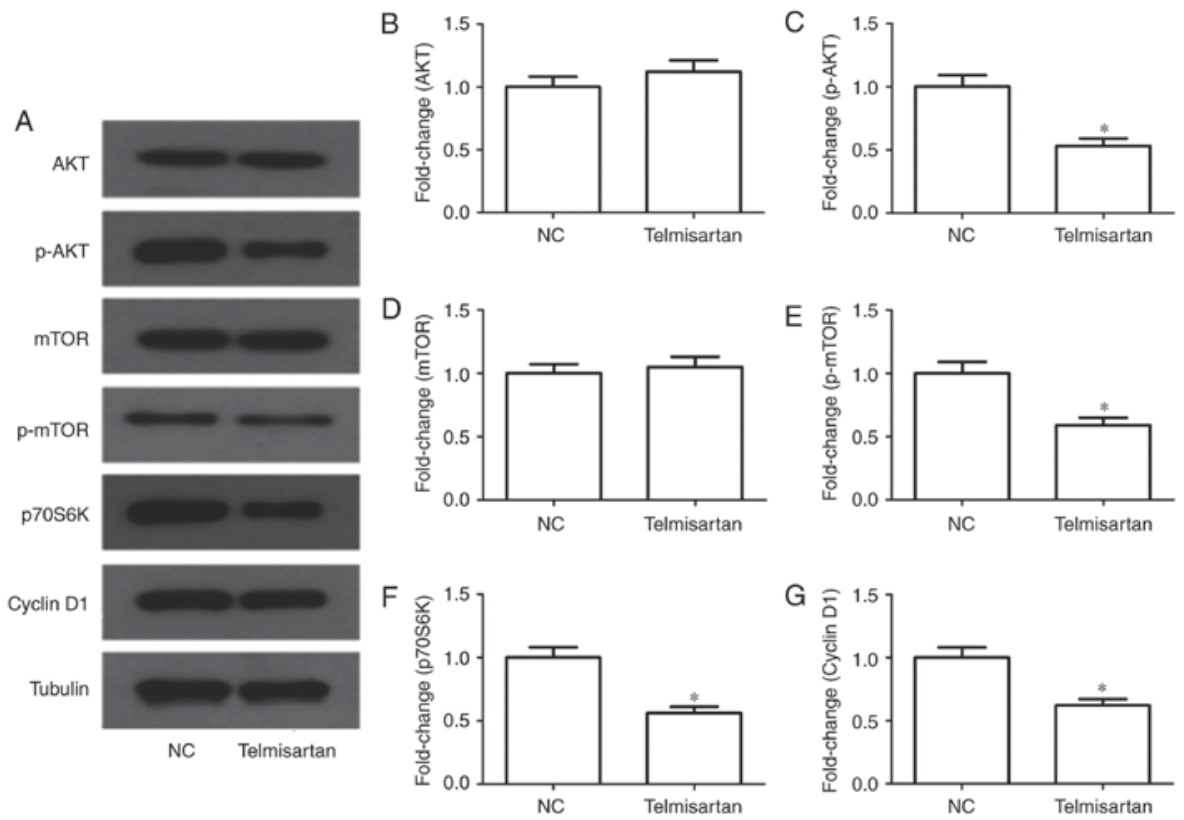

Figure 4. Effects of telmisartan on the PI3K signaling pathway in A549 cells. (A) Expression levels of AKT, p-AKT, mTOR, p-mTOR, p70S6K and cyclin D1 were measured in A549 cells treated with $20 \mu \mathrm{M}$ telmisartan by western blot analysis. (B-G) The relative protein levels of AKT, p-AKT, mTOR, p-mTOR, p70S6K and cyclin D1 compared with the control group. * $\mathrm{P}<0.05$, compared with NC group. PI3K, phosphoinositide 3-kinase; p-AKT, phosphorylated RAC serine/threonine-protein kinase; mTOR, mechanistic target of rapamycin; p70S6K, p70-S6 kinase; NC, negative control. 
published data have demonstrated an association between Ang II and cancer development $(22,23)$. Penafuerte et al (24) revealed that Ang II is a major upstream regulator of cancer cachexia. Recently, studies have reported that Ang II stimulates angiogenesis and tumor growth, particularly in breast and pancreatic cancer $(25,26)$. The local production of Ang II in gastric cancer has been indicated to promote lymph node metastasis and cancer progression (27). By contrast, ARBs have been demonstrated to be effective in reducing tumor growth, angiogenesis and metastasis in mouse models in vivo $(28,29)$. Ang II binds two receptor subtypes to mediate its biological effects, AT1R and AT2R (30). Studies have demonstrated that the main functions of Ang II in tumor growth are mediated by the AT1R (31). ARBs block the activation of AT1R, thus inhibiting the renin-angiotensin system (32).

In the present study, NSCLC A549 cells were treated with telmisartan. The results of the CCK- 8 proliferation assay indicated that telmisartan could inhibit A549 proliferation in a dose- and time-dependent manner. In transwell assays, telmisartan significantly inhibited the invasion and migration of A549. Telmisartan is a specific AT1R blocker, which has the strongest binding affinity for AT1R in ARBs $(16,33)$. It has previously been reported that Ang II can potentiate breast cancer cell migration (25). Godugu et al (7) revealed that telmisartan could enhance the anticancer effect on A549 cells; however, whether telmisartan can inhibit proliferation, promote migration, invasion and apoptosis in lung cancer cells has not, to the best of our knowledge, been studied. The results of the present study demonstrated that telmisartan could inhibit A549 cell proliferation and migration.

The results of the apoptosis assay indicated that telmisartan had a greater effect in early apoptosis, compared with late apoptosis, indicating that the Bcl-2 intrinsic mitochondrial apoptosis pathway was activated. The results of western blot analysis demonstrated that the expression of the pro-apoptotic proteins caspase- 3 and Bax increased in the telmisartan-treated groups whereas that of the anti-apoptotic protein Bcl-2 decreased. Bcl-2 is a negative regulator of apoptosis, whereas Bax and caspase- 3 are positive regulators of apoptosis (34). Apoptosis is an important antitumor target, and a number of antitumor drugs function by inducing apoptosis (35). The activation of apoptosis is regulated via multiple signaling pathways, of which PI3K/AKT is one of the more important (36). The results of western blot analysis indicated that levels of p-AKT, p-mTOR, p70S6k and cyclin D1 were significantly decreased in the telmisartan-treated group, which indicated that telmisartan may exert an antitumor effect through the regulation of apoptosis via the PI3K/AKT pathway. The PI3K/AKT pathway can mediate cell survival signals via the Bcl-2 family (37). AKT has direct effects on the effectors of the apoptotic pathway, including Bcl-2 (38). Bcl-2 activity is regulated via p-AKT in various cell types (39). AKT phosphorylates Bax, disrupting its interaction with Bcl-XL to protect cells from apoptosis (40). In addition, AKT can phosphorylate Bcl-2, making it resistant to protein degradation and ultimately protecting the cell from apoptosis (41). The effect of mTOR on Bcl-2 is similar to that of AKT (42). Additionally, p70S6K and cyclin D1 may also be involved in pathways that telmisartan effects in cancer cells. Cyclin D1 and p70S6K are located downstream of the PI3K/AKT pathway, which is closely associated with cell apoptosis $(43,44)$. Cyclin D1 is a member of the cyclin D family of proteins that serve a pivotal role in facilitating the cell cycle (45). The expression of cyclin D1 is increased in different types of tumor tissues (46). The present results were consistent with these studies (41-46), which indicated that telmisartan inhibited signaling via the PI3K/AKT pathway in A549 cells, and reduced the phosphorylation of mTOR, p70S6K and cyclin D1. In summary, the downregulation of the PI3K/AKT pathway may have contributed to the inhibitory effect of telmisartan on A549 cells.

In conclusion, the present study demonstrated that telmisartan could inhibit the proliferation, invasion and migration of lung cancer cells and promote their apoptosis via the PI3K/AKT signaling pathway. The present study provides a prospect for further clinical research of telmisartan in lung cancer treatment.

\section{References}

1. Pan ST, Zhou ZW, He ZX, Zhang X, Yang T, Yang YX, Wang D, Qiu JX and Zhou SF: Proteomic response to 5,6-dimethylxanthenone 4-acetic acid (DMXAA, vadimezan) in human non-small cell lung cancer A549 cells determined by the stable-isotope labeling by amino acids in cell culture (SILAC) approach. Drug Des Devel Ther 9: 937-968, 2015.

2. Han ML, Zhao YF, Tan CH, Xiong YJ, Wang WJ, Wu F, Fei Y, Wang L and Liang ZQ: Cathepsin L upregulation-induced EMT phenotype is associated with the acquisition of cisplatin or paclitaxel resistance in A549 cells. Acta Pharmacol Sin 37: $1606-1622,2016$

3. Kallianos A, Tsimpoukis S, Zarogoulidis P, Darwiche K, Charpidou A, Tsioulis I, Trakada G, Porpodis K, Spyratos D, Panoutsopoulos A, et al: Measurement of exhaled alveolar nitrogen oxide in patients with lung cancer: A friend from the past still precious today. Onco Targets Ther 6: 609-613, 2013

4. Jiang M, Zhong T, Zhang W, Xiao Z, Hu G, Zhou H and Kuang H: Reduced expression of miR-205-5p promotes apoptosis and inhibits proliferation and invasion in lung cancer A549 cells by upregulation of ZEB2 and downregulation of erbB3. Mol Med Rep 15: 3231-3238, 2017.

5. Yuan Y, Zheng S, Li Q, Xiang X, Gao T, Ran P, Sun L, Huang Q, $\mathrm{Xie} F, \mathrm{Du} \mathrm{J}$ and Xiao C: Overexpression of miR-30a in lung adenocarcinoma A549 cell line inhibits migration and invasion via targeting EYA2. Acta Biochim Biophys Sin (Shanghai) 48: 220-228, 2016.

6. Keith RL and Miller YE: Lung cancer chemoprevention: Current status and future prospects. Nat Rev Clin Oncol 10: 334-343, 2013.

7. Godugu C, Patel AR, Doddapaneni R, Marepally S, Jackson T and Singh M: Inhalation delivery of Telmisartan enhances intratumoral distribution of nanoparticles in lung cancer models. J Control Release 172: 86-95, 2013.

8. Matsuyama M, Funao K, Kuratsukuri K, Tanaka T, Kawahito Y, Sano H, Chargui J, Touraine JL, Yoshimura N and Yoshimura R: Telmisartan inhibits human urological cancer cell growth through early apoptosis. Exp Ther Med 1: 301-306, 2010.

9. Li P, Koike T, Jiang HY, Wang ZH, Kawata Y and Oshida Y: Acute treatment with candesartan cilexetil, an angiotensin II type 1 receptor blocker, improves insulin sensitivity in high-fructose-diet-fed rats. Horm Metab Res 44: 286-290, 2012.

10. Marquardt G, Schulz TF and Schweighofer B: Angiogenesis in cancer. Nature 407: 249-257, 2012.

11. Celus W, Di Conza G, Oliveira AI, Ehling M, Costa BM, Wenes M and Mazzone M: Loss of caveolin-1 in metastasis-associated macrophages drives lung metastatic growth through increased angiogenesis. Cell Rep 21: 2842-2854, 2017.

12. Imai N, Hashimoto T, Kihara M, Yoshida S, Kawana I, Yazawa T, Kitamura H and Umemura S: Roles for host and tumor angiotensin II type 1 receptor in tumor growth and tumor-associated angiogenesis. Lab Invest 87: 189-198, 2007.

13. Hinsley EE, de Oliveira CE, Hunt S, Coletta RD and Lambert DW: Angiotensin 1-7 inhibits angiotensin II-stimulated head and neck cancer progression. Eur J Oral Sci 125: 247-257, 2017. 
14. Chan SMH, Lau YS, Miller AA, Ku JM, Potocnik S, Ye JM Woodman OL and Herbert TP: Angiotensin II causes $\beta$-cell dysfunction through an ER stress-induced proinflammatory response. Endocrinology 158: 3162-3173, 2017.

15. de Araújo Júnior RF, Leitão Oliveira AL, de Melo Silveira RF, de Oliveira Rocha HA, de França Cavalcanti P and de Araújo AA: Telmisartan induces apoptosis and regulates Bcl-2 in human renal cancer cells. Exp Biol Med (Maywood) 240: 34-44, 2015.

16. Sukumaran S, Patel HJ and Patel BM: Evaluation of role of telmisartan in combination with 5-fluorouracil in gastric cancer cachexia. Life Sci 154: 15-23, 2016.

17. Lee LD, Mafura B, Lauscher JC, Seeliger H, Kreis ME and Gröne J: Antiproliferative and apoptotic effects of telmisartan in human colon cancer cells. Oncol Lett 8: 2681-2686, 2014.

18. Funao K, Matsuyama M, Kawahito Y, Sano H, Chargui J, Touraine JL, Nakatani T and Yoshimura R: Telmisartan is a potent target for prevention and treatment in human prostate cancer. Oncol Rep 20: 295-300, 2008.

19. Funao K, Matsuyama M, Kawahito Y, Sano H, Chargui J, Touraine JL, Nakatani T and Yoshimura R: Telmisartan as a peroxisome proliferator-activated receptor- $\gamma$ ligand is a new target in the treatment of human renal cell carcinoma. Mol Med Rep 2: 193-198, 2009

20. Li J, Chen L, Yu P, Liu B, Zhu J and Yang Y: Telmisartan exerts anti-tumor effects by activating peroxisome proliferator-activated receptor- $\gamma$ in human lung adenocarcinoma A549 cells. Molecules 19: 2862-2876, 2014.

21. Wu TT, Niu HS, Chen LJ, Cheng JT and Tong YC: Increase of human prostate cancer cell (DU145) apoptosis by telmisartan through PPAR-delta pathway. Eur J Pharmacol 775: 35-42, 2016

22. Cambados N, Walther T, Nahmod K, Tocci JM, Rubinstein N, Böhme I, Simian M, Sampayo R, Del Valle Suberbordes M, Kordon EC and Schere-Levy C: Angiotensin-(1-7) counteracts the transforming effects triggered by angiotensin II in breast cancer cells. Oncotarget 8: 88475-88487, 2017.

23. Sobczuk P, Szczylik C, Porta C and Czarnecka AM: Renin angiotensin system deregulation as renal cancer risk factor. Oncol Lett 14: 5059-5068, 2017.

24. Penafuerte CA, Gagnon B, Sirois J, Murphy J, MacDonald N and Tremblay ML: Identification of neutrophil-derived proteases and angiotensin II as biomarkers of cancer cachexia. Br J Cancer 114 680-687, 2016

25. Rodrigues-Ferreira S, Abdelkarim M, Dillenburg-Pilla $P$, Luissint AC, di-Tommaso A, Deshayes F, Pontes CL, Molina A, Cagnard N and Letourneur F: Angiotensin II facilitates breast cancer cell migration and metastasis. PLos One 7: e35667, 2012.

26. Masamune A, Hamada S, Kikuta K, Takikawa T, Miura S, Nakano E and Shimosegawa T: The angiotensin II type I receptor blocker olmesartan inhibits the growth of pancreatic cancer by targeting stellate cell activities in mice. Scand J Gastroenterol 48 : 602-609, 2013

27. Kinoshita J, Fushida S, Harada S, Yagi Y, Fujita H, Kinami S, Ninomiya I, Fujimura T, Kayahara M, Yashiro M, et al: Local angiotensin II-generation in human gastric cancer: Correlation with tumor progression through the activation of ERK1/2, NF-kappaB and survivin. Int J Oncol 34: 1573-1582, 2009.

28. Arafat HA, Gong Q, Chipitsyna G, Rizvi A, Saa CT and Yeo CJ: Antihypertensives as novel antineoplastics: Angiotensin-I-converting enzyme inhibitors and angiotensin II type 1 receptor blockers in pancreatic ductal adenocarcinoma. J Am Coll Surg 204: 996-1005, 2007.

29. George AJ, Thomas WG and Hannan RD: The renin-angiotensin system and cancer: Old dog, new tricks. Nat Rev Cancer 10 745-759, 2010

30. Liles C, Li H, Veitla V, Liles JT, Murphy TA, Cunningham MW Yu X and Kem DC: AT2R autoantibodies block angiotensin II and AT1R autoantibody-induced vasoconstriction. Hypertension 66 : $830-835,2015$
31. Kosugi M, Miyajima A, Kikuchi E, Kosaka T, Horiguchi Y and Murai M: Effect of angiotensin II type 1 receptor antagonist on tumor growth and angiogenesis in a xenograft model of human bladder cancer. Hum Cell 20: 1-9, 2007.

32. Zhang J, Liu J, Chen J, Li X, Wu Y, Chen H, Wu W, Zhang K and $\mathrm{Gu}$ L: Angiotensin receptor blockers (ARBs) reduce the risk of lung cancer: A systematic review and meta-analysis. Int J Clin Exp Med 8: 12656-12660, 2015.

33. Kakuta H, Sudoh K, Sasamata M and Yamagishi S: Telmisartan has the strongest binding affinity to angiotensin II type 1 receptor: Comparison with other angiotensin II type 1 receptor blockers. Int J Clin Pharmacol Res 25: 41-46, 2005.

34. Wei JC, Zhang T and Yang P: Effect of gambogic acid on cell apoptosis and expressions of Bax, Bcl-2 and Caspase- 3 in colorectal cancer cells with. J Pract Med 2016.

35. Mao YQ, Li XR and Lei S: Effect of several anti-tumor drugs on apoptosis induction in jurkat cell line. Zhongguo Shi Yan Xue Ye Xue Za Zhi 14: 681-685, 2006 (In Chinese).

36. González-Pérez PP and Cárdenas-García M: Modeling and simulation of molecular mechanism of action of dietary polyphenols on the inhibition of anti-apoptotic PI3K/AKT pathway. Comput Mol Biosci 3: 39-52, 2013.

37. Guo H, Cui H, Peng X, Fang J, Zuo Z, Deng J, Wang X, Wu B, Chen K and Deng J: Modulation of the PI3K/Akt pathway and Bcl-2 family proteins involved in chicken's tubular apoptosis induced by nickel chloride $\left(\mathrm{NiCl}_{2}\right)$. Int J Mol Sci 16: 22989-23011, 2015.

38. Phatak NR, Stankowska DL and Krishnamoorthy RR: Bcl-2, $\mathrm{Bcl}-\mathrm{xL}$ and $\mathrm{p}-\mathrm{AKT}$ are involved in neuroprotective effects of transcription factor Brn3b in an ocular hypertension rat model of glaucoma. Mol Vis 22: 1048-1061, 2016.

39. Song T, Wang L, Mo Z, Mao L, Ma X, Niu R, Gu K, Yan R, Ma P, Qi Y and Jiao Q: Expression of p-Akt in ovarian serous carcinoma and its association with proliferation and apoptosis. Oncol Lett 7: 59-64, 2014.

40. Premkumar DR, Jane EP, DiDomenico JD, Vukmer NA, Agostino NR and Pollack IF: ABT-737 synergizes with bortezomib to induce apoptosis, mediated by bid cleavage, bax activation, and mitochondrial dysfunction in an Akt-dependent context in malignant human glioma cell lines. J Pharmacol Exp Ther 341: 859-872, 2012.

41. Bratton MR, Duong BN, Elliott S, Weldon CB, Beckman BS, McLachlan JA and Burow ME: Regulation of ERalpha-mediated transcription of Bcl-2 by PI3K-AKT crosstalk: Implications for breast cancer cell survival. Int J Oncol 37: 541-550, 2010.

42. Hamunyela RH, Serafin AM and Akudugu JM: Strong synergism between small molecule inhibitors of HER2, PI3K, mTOR and Bcl-2 in human breast cancer cells. Toxicol In Vitro 38: 117-123, 2017.

43. Halacli SO and Dogan AL: FOXP1 regulation via the PI3K/AKT/p70S6K signaling pathway in breast cancer cells. Oncol Lett 9: 1482-1488, 2015.

44. Liu W, Ren H, Ren J, Yin T, Hu B, Xie S, Dai Y, Wu W, Xiao Z, Yang $\mathrm{X}$ and Xie D: The role of EGFR/PI3K/AKT/cyclinD1 signaling pathway in acquired middle ear cholesteatoma. Mediators Inflamm 2013: 651207, 2013.

45. Zhao S, Yi M, Yuan Y, Zhuang W, Zhang D, Yu X, Chen X, Teng B, Guan Z and Zhang Y: Expression of AKAP95, Cx43, CyclinE1 and CyclinD1 in esophageal cancer and their association with the clinical and pathological parameters. Int J Clin Exp Med 8: 7324-7332, 2015.

46. Cheng R, Liu YJ, Cui JW, Yang M, Liu XL, Li P, Wang Z, Zhu LZ, Lu SY, Zou L, et al: Aspirin regulation of c-myc and cyclinD1 proteins to overcome tamoxifen resistance in estrogen receptor-positive breast cancer cells. Oncotarget 8: 30252-30264, 2017. 